\title{
Evaluation of Chemotherapy Drugs Carboplatin and Temozolamide in Pharmaceutical Formulations and Biosamples via Capillary Zone Electrophoresis Approach
}

\author{
Nawal A. Alarfaj, Maha F. El-Tohamy ${ }^{\dagger, *}$ \\ Department of Chemistry, College of Science, King Saud University, P.O. Box 22452, Riyadh 11495, \\ Saudi Arabia nalarfaj@ hotmail.com, star2000star@gmail.com \\ $†$ Permanent address: General Administrative of Medical Affairs, Zagazig University, Egypt \\ *E-mail: star2000star@gmail.com
}

doi: $10.20964 / 2018.05 .55$

Received: 15 January 2018 / Accepted: 13 March 2018 / Published: 10 April 2018

\begin{abstract}
A simultaneous separation process of two anticancer drugs carboplatin and temozolamide in their binary mixture using capillary zone electrophoresis method has been introduced in this study. Under full optimized conditions a fused silica capillary was used to carry out the electrophoretic separation using a background electrolyte $50 \mathrm{mmol} \mathrm{L}$ acetate buffer of $\mathrm{pH}=3.6$ which was run at potential 20 $\mathrm{kV}$, hydrodynamic injection $8 \mathrm{~s}$ and 60 mbar pressure. The capillary cartridge temperature was adjusted at $30^{\circ} \mathrm{C}$ and a diode array detector was utilized to record the separation peaks in the presence of internal standard phenylethylamine solution at $330 \mathrm{~nm}$. Excellent electrophoretic separation was achieved over linear concentration ranges of 10-240 and 5-100 $\mathrm{g} \mathrm{mL}^{-1}$ with correlation coefficients of 0.9996 and 0.9993 for carboplatin and temozolamide, respectively. The obtained detection and quantification limits were found to be 2.5 and $7.4 \mu \mathrm{g} \mathrm{mL}^{-1}$ for carboplatin, while, for temozolamide were found to be 1.3 and $4.3 \mu \mathrm{g} \mathrm{mL} \mathrm{m}^{-1}$. This analytical approach was validated and the results were compared with those reported by other reported methods.
\end{abstract}

Keywords: Capillary zone electrophoresis; Carboplatin; Temozolamide; Chemotherapy; Pharmaceutical formulations; Biological fluids

\section{$\underline{\text { FULL TEXT }}$}

(C) 2018 The Authors. Published by ESG (www.electrochemsci.org). This article is an open access article distributed under the terms and conditions of the Creative Commons Attribution license (http://creativecommons.org/licenses/by/4.0/). 